\title{
New Consortial Model for E-Books Acquisitions
}

\section{Luke Swindler}

\begin{abstract}
E-books constitute major challenges for library collections generally and present fundamental problems for consortial collection development specifically. The Triangle Research Libraries Network (TRLN) and Oxford University Press (OUP) have created a mutually equitable and financially sustainable model for the consortial acquisition of e-books coupled with print titles needed to support instruction and research across the disciplinary spectrum within a transitional framework that is acceptable to users while moving both libraries and publishers to a decidedly electronic environment for monographs. Working with YBP Library Services, TRLN and OUP developed a flexible vending model for systematically increasing e-books acquisitions in tandem with reducing print intake over time and keeping net costs constant that other consortia and publishers would find useful. This article focuses on creating an acceptable and sustainable model that allows libraries to shift to e-books and the implications for traditional cooperative collection development. The research reports on the principles undergirding the pilot, how it developed, challenges encountered and lessons learned, librarian and user reactions to this format shift, and resulting philosophical and practical evolutions in consortial approaches to monographic acquisitions and understandings of what constitutes cooperative collections success in a digital environment.
\end{abstract}

\section{E-Books Challenges to Collections \& Cooperation}

E-books represent more than another disruptive networked technology for library collections. Precisely because e-books do not supersede the need to continue the acquisition of corresponding print analogs, as has been the norm with e-journals, they pose a fundamental challenge to how libraries can and should develop monographic collections where both tangible and electronic formats are needed in a shared ecosystem.

Libraries acting either alone or in consortia cannot simply shift collecting from print to e-books, particularly in terms of meeting legitimate reader needs for long-form monographs in the humanities and nonquantitative social sciences. No significant findings in the proliferating published research have emerged to contradict this understanding. ${ }^{1}$

The perennial debates about e-books versus print books fundamentally miss the point because they are predicated upon a false dichotomy between the two formats.

Luke Swindler is Collections Management Officer for the University Library at the University of North Carolina at Chapel Hill; e-mail: luke_swindler@unc.edu. The author wants to acknowledge and thank Mona Couts, Lisa Croucher, Patricia Dominguez, Teddy Gray, Carol Hunter, Will Owen, Greg Raschke, and John Vickery for reading and commenting on earlier versions of this article. (C) 2016 Luke Swindler, Attribution-NonCommercial (http://creativecommons.org/licenses/by-nc/3.0/) CC BY-NC. 
As one recent study concluded, "Across the academic community, and even within the publishing industry, there is a general belief that print formats and e-books are not in an either-or competition." ${ }^{2}$ Within this context, a newer study highlighted the "need to examine print and electronic formats as related sources that can be used together and enhance one another, rather than as oppositional resources that should be considered as either/or options," and calls for a better understanding of the interaction and interrelatedness of these two formats. ${ }^{3}$ Addressing these issues of print and e-book complementarity in supporting the academic enterprise is a key element of the innovative collections program that forms the core of this article.

As a rule, e-books and their print analogs do not so much compete as complement one another, with readers generally preferring electronic versions for certain kinds of quick study and consultation but paper versions for long, linear reading - at least for the present. As a consequence, reader surveys do not indicate a strong preference for either print or e-books per se, because the choice is dependent upon "the activity at hand." ${ }^{4}$ Additionally, each format "lends itself to varying learning styles" among undergraduates. ${ }^{5}$

Because users may want to interact with the same texts in different ways, depending on the task and the stage in the reading and research process, to be successful, cooperative collection development models must meet these multiple and symbiotic needs by offering both formats when appropriate in a fiscally affordable and sustainable ecosystem. At the same time, librarians and publishers need to understand better how the availability of e-books impacts on corresponding print book use-and such a study should be done with monographs across the interdisciplinary spectrum and on a multiyear basis to provide solid documentation on this interaction.

E-books also force librarians to rethink how they can cooperatively build monographic collections that over time will increasingly consist of digital rather than physical books and do so in ways that are acceptable to both publishers and patrons. Given financial pressures, libraries cannot afford to shift to the typically more expensive ebooks on a title-by-title basis while continuing to acquire print copies on the current scale. Conversely, publishers need to protect their revenue streams that cover the fixed costs of producing monographs and realize a reasonable profit while adjusting to a rapidly changing market that increases the risks of publishing books in any format.

At the core of this second challenge is how can libraries collectively acquire or, alternatively, share e-books. Current consortial arrangements based on complex price multipliers that often limit simultaneous access to shared e-book pools and typically result in inequitable costs and benefits to individual library participants represent less than optimal solutions. Conversely, attempts to share entire e-books predicated upon print-based interlibrary lending practices are wrongheaded and, in any case, will not be acceptable to publishers that depend primarily on book sales. Even the highly touted Occam's Reader project ${ }^{6}$ is not an Occam's razor solution, beginning with the delays in patron access and high transaction costs of library-mediated borrowing and lending that make it fundamentally retrograde.

The new solutions required, moreover, will not replicate the relatively static arrangements for print publishing and paper-based cooperative collection development. Rather, they must constitute flexible models that can accommodate ever-evolving technologies, unpredictable economic dynamics, and changing reader preferences.

The evolving and complex nature of e-book acceptance is best illustrated by comparing the results of studies documenting growing student acceptance of e-books over the last decade while highlighting a preference "to do course-related activities with paper and ink." 7 Success in this unstable environment therefore requires that all parties experiment to create a shared flexible ecosystem for vending books in multiple formats 
that represents a clear improvement over existing arrangements while simultaneously continuing cooperative collection development by enhancing the ability of libraries to share these electronic resources.

Faced with these complexities, librarians are struggling to build new collections paradigms that incorporate e-books with print in a consortial model that is efficient in terms of acquisitions and access, equitable in meeting the needs of both publishers that sell books and institutions that buy them, acceptable to readers, and fiscally sustainable over the long term. The Triangle Research Libraries Network (TRLN) partnership with Oxford University Press (OUP) addresses these challenges of acquiring books in dual formats, together with assessing librarian and reader responses to solutions, while enhancing long-established cooperative collection development by undertaking innovative approaches that can be used by other publishers and librarians.

\section{Building upon Original Principles}

One of the earliest continuously operating cooperative collection development programs began in the 1930s among the libraries that now constitute TRLN: University of North Carolina at Chapel Hill (UNC), Duke University, North Carolina State University, and North Carolina Central University. This consortium has been successful over many decades because it always focused on providing the optimal level of support for the academic enterprise rather than saving money per se. As noted in its definitive history, "If cooperation is to succeed, it must therefore emphasize institutional advancement and enhanced service to users." 8 Guided by this broad vision, librarians have built interdependent and interlocked collections based on each library's self-interest that "provide a depth of coverage and that would be impossible for individual institutions to achieve on their own." ${ }^{\prime}$

In achieving this goal, "librarians have come to realize that the subjects and materials covered by cooperative agreements must not be so central to research that faculty insist they be available locally." 10 TRLN cooperation in the past therefore focused on specialized categories of tangible resources with low use that were of primary interest to specific populations, such as government documents, microforms, foreign-language titles, and retrospective acquisitions. Because current English-language academic monographs are central to supporting instruction and research and expected to register significant use, until recently systematically sharing collecting responsibilities for them in a world of only print books has not been possible even when ready access is provided.

Recently, TRLN began exploring ways to formulate a new model for cooperation and extend it beyond tangible media to encompass e-books. Over the previous decade, the consortium's librarians learned how to cooperatively license and acquire ownership of e-journals through joint publisher "big deals" to leverage their collections budgets and maximize the digital resources available to faculty and students. The newness of e-books and lack of standard vending schemas created both new sets of obstacles as well as opportunities to devise win-win models that would work for publishers, vendors, libraries, and users.

Under the rubric of TRLN United: One Collection, One Community, librarians have "a vision of breaking down any remaining barriers to a long-standing goal of one research collection, serving one user community." ${ }^{11}$ While the overarching aim of cooperation continues to be providing the greatest possible breadth and depth of collections across the consortium, the critical questions now revolve around how to successfully cooperate on e-resources in ways that both take full advantage of the inherent characteristics of digital resources and also are acceptable to users. Within this context, the 2011 TRLN Beyond Print symposium was part of a larger "project to develop new business models and licensing terms for the cooperative acquisition of e-books."12 


\section{TRLN/OUP Pilot in Context}

TRLN's partnership with OUP to expand cooperative collection development to ebooks has taken place within the larger matrix of three fundamental transformations: the means by which research libraries build collections in the 21st century; the impact of e-resources in dramatically expanding the scale of collections; and a revolution in how to measure cooperative collection development success in a digital universe, especially since e-books typically cannot be shared via interlibrary lending. All three of these developments have redefined the parameters of what libraries and publishers have attempted in the past and reformulated the pivotal role that vendors such as YBP Library Services (YBP) can play in supporting cooperative acquisitions. This in turn highlights the growing importance for vendors of a business model predicated upon providing services that publishers value and librarians will pay for.

Over the last generation, research libraries have changed the way they acquire monographs from mainly title-by-title selection to categorical purchases of large blocs of titles. This development has occurred for several reasons. Pressure to use staff and budgets as efficiently and effectively as possible is pervasive. Libraries need to create more time for selectors to spend on complex acquisitions and simultaneously provide higher-level instructional and research services. Advances in vendors' computer capabilities have made sophisticated acquisition plans possible for developed publishing markets. More recently, the rapidly expanding universe of electronic resources and the fundamentally different economics of e-books are changing the selection universe.

The major user impetus for this shift has been the expectation that libraries provide faculty and students with the widest array of relevant monographs as soon as possible, coupled with a rapidly escalating acceptance of e-books. This transformation improves support for instruction and research by increasing the number of monographs available and providing many of them earlier insofar as e-books increasingly become available before print. It also simultaneously accelerates the collections' evolution to a $24 / 7$ virtual service.

This change in how academic libraries acquire resources, together with the shift from tangible to increasingly if not predominantly networked collections, represented a fundamental transition from an analog world of relative book scarcity to one of digital abundance as growth in the scale of titles available to patrons has outstripped even the most impressive expansion of collections that marked the so-called "golden age" of research library acquisitions in the mid-twentieth century.

As a consequence of these intertwined transformations in the nature and scale of acquisitions, TRLN and OUP concentrated on creating a financially sustainable consortial acquisitions model predicated upon vending the entire print and e-books output of publishers participating in OUP's University Press Scholarship Online (UPSO) enterprise. ${ }^{13}$ Since monographs have been a central focus of TRLN cooperation, the deliberate and systematic widespread duplication of e-books, coupled with a single shared print copy of a limited number of titles within the consortium as a result of this pilot, posed a fundamental challenge to long-established understandings of cooperative collection development and how libraries share resources.

In the traditional universe of tangible media, TRLN measured cooperative success by maximizing the number of unique titles within the consortium through minimizing duplication, with the latter being part and parcel of how each library freed up collections dollars to achieve the former. It operationalized this model for cooperative acquisition of specialized and low-use resources through expedited interlibrary borrowing among its member institutions at no cost to patrons.

Within this new consortial e-books acquisitions paradigm, predicated upon vending the entire print and e-books output of UPSO publishers, cooperative success would 
be achieved and assessed by how well TRLN leveraged financial resources to ensure each institution offered its users the same digital products in terms of immediate and unmediated access - and did so on a scale that could not be achieved if the libraries acted individually. This approach anticipated the recent Association of Research Libraries' call for a multi-institutional collaboration on large aggregations of content as well as a "shift from thinking of collections as products to understanding collections as components of the academy's knowledge resources." 14 The resulting TRLN experiment also entailed learning how to effectively share a single print copy of newly published high-visibility and potentially high-use books in a common offsite facility on terms that would be acceptable to faculty and students.

Creating a new model for digital cooperative collection development is what the TRLN/OUP pilot is all about-and it is one other libraries can adopt/adapt. With this program, for approximately the same pre-existing aggregate spend, TRLN committed to automatically purchase the entire monographic output from participating publishers either as separately and individually owned e-books or as single shared print copies - and for some subjects acquire both formats so patrons would be willing to accept the overall shift to e-books.

The focus of cooperative purchasing for these monographs moved from ad hoc titleby-title selection to systematic wholesale acquisition, from individual subject librarian actions to consortial policy-level decisions, and from minimizing dollars spent on duplicate single titles to optimizing expenditures for the same set of titles. Cooperation in a digital world thereby inverted the traditional metric for success from uniqueness of titles held to extensiveness of duplication within the consortium.

Some subject librarians within TRLN asked what the shift to e-books meant for their individual roles in cooperative collection development since digital resources cannot be shared through borrowing as print books can. Whereas selectors might not buy a specialized or expensive title if a print book were held elsewhere within the consortium, they would feel compelled to do so because users cannot borrow an e-book. While at the micro-level of title-by-title acquisition, subject librarians might remain concerned that selecting e-books means they are not cooperating, at the macro-level of en bloc acquisitions, TRLN cooperation not only continues but also expands. Yet collections librarians still need to work hard to ensure that the net effects of these contradictory micro- and macrotrends remain positive for both the consortium and its patrons.

\section{Publisher E-books Partnership Precedents}

Building upon a long history of successful cooperative collection development programs going back decades for tangible media that distributed subject, language, and format responsibilities among member libraries to minimize overlap and maximize breadth of coverage from many publishers, the TRLN/OUP pilot is best understood within the larger mosaic of a hierarchical e-book strategy that developed over time. Years earlier, UNC librarians began laying groundwork that led to the partnership with OUP by spending the time and effort to develop deep relationships with major content providers predicated upon the new possibilities and fundamentally different economics of digital publishing. Moreover, they did so within a long-term win-win framework rather than with the objective of merely purchasing e-books or creating yet another buying club for them that typically characterizes consortial acquisitions arrangements.

In 2006, UNC began its first large-scale shift to e-books in lieu of print by concentrating on making deals with major academic publishers. This action was part of the central collections goal in its 2005-2010 strategic plan to "move aggressively to acquire high quality electronic content that is a good cost value." ${ }^{15} \mathrm{~A}$ focus on purchasing the entire 
e-books output of core presses would become the salient feature of the TRLN/OUP pilot that distinguishes it from the typical omnibus and opportunistic approaches to e-book acquisitions of other consortia. This strategy also required allocating funds off the top of the acquisitions budget on the model of the e-journals "big deals" to ensure the program's continuance as a collections priority,

Because Springer was the largest academic publisher in terms of monographs annually produced, had the greatest number of e-books, and offered a library- and user-friendly vending platform, its output was the first to be converted from print to electronic acquisitions. UNC has continued to acquire all e-book packages on the SpringerLink platform, even with the total number of titles surging as this publisher began distributing the monographs of professional and scholarly societies and specialized presses. The impact of concentrating on major "publishers aggregators" is demonstrated by the rapidly growing numbers of English-language titles included in the Springer e-books packages: their total shot up from 3,021 in 2010 to 4,830 in 2012, then to 5,835 for 2013, with a projected increase of 7\%-9\% for 2014 .

UNC would subsequently fold these digital acquisitions into TRLN's consortial Springer "big deal" so as to leverage the contract's e-journal expenditures to keep the cost of its rapidly escalating numbers of e-books as low as possible, as well as to ensure that their acquisition remains a budgetary priority. As a consequence of this approach, UNC's mean price per Springer e-book acquired has been consistently declining because the growth in titles has been much less than the increase in their cost within the inflation cap of a consortial contract.

As part of this format change, UNC purchased the entire Springer e-books archive then available, in the process learning how to leverage such a major collections shift to secure extremely advantageous financial terms. Whenever affordable, UNC subsequently would couple other wholesale monographic front-list conversions from print to electronic with acquiring the entire corresponding archive to realize the most favorable pricing.

To make this format change acceptable to faculty and students, UNC librarians emphasized that this conversion would expand monographic intake and guarantee complete acquisitions. The library also committed to purchase a print duplicate of any Springer e-book upon request and without question. These two incentives would become part of UNC's standard practice to help users accept shifts from print to ebooks. Librarians also learned that the cost of offering to purchase print duplicates on demand was insignificant. Over the decade since this shift to e-books, UNC estimates that it has deliberately purchased print duplicates of at most a score of Springer titles.

The format shift for Springer monographs emphatically demonstrated the significance of a move from the print book world of scarcity to the e-books universe of abundance in terms of expanding support for the academic enterprise. When UNC was purchasing Springer print monographs on a title-by-title basis, it could never buy more than half the output, even with a significant discount from YBP. With the shift to en bloc acquisition of e-books, it now could acquire nearly all of the publisher's monographs with no YBP discount-and without spending library selectors' time to do so. The results have been dramatic. Whereas, in early 2015, UNC's online catalog listed 23,298 Springer print books with publication dates spanning 144 years back to 1871 , over only the nine years since the conversion to electronic, the OPAC indicated ownership of 46,673 Springer e-books. UNC's early experience with the wholesale acquisition of e-books in lieu of print proved that "big deals" could be good deals for monographs, as has been the case for e-journals. ${ }^{16}$

UNC subsequently developed - and TRLN has in effect followed - a comprehensive e-books strategy along the lines outlined above. With a concentration on large publish- 
ers and aggregators, this strategy looks at many indications of value-which go beyond price to consider such issues as level of discoverability; unlimited simultaneous users as the default; DRM restrictions; conditions of use such as the ability to download, save, and e-mail; easy accessibility via mobile devices; and e-archiving arrangements.

The importance of selecting those publishers with optimal platforms as candidates for wholesale conversions of monographic acquisitions to e-books is critical, because user acceptance of e-texts is strongly predicated upon their user-friendliness. As a recent literature survey on librarians' reluctance to shift to e-books and their corresponding perception of readers' resistance noted, "Patrons do not use e-books because they find the experience of using e-books incongruous with their experience of using other electronic resources, and many of the unexpected limitations they encounter when using e-books are not inherent to the format." ${ }^{17}$ In brief, poor e-book platform choices will result in negative patron experiences with e-texts.

Building on UNC's successful experience with Springer, the e-books selection hierarchy begins with recommended core "publisher aggregators" that offer both their own and other imprints on a library- and reader-friendly platform as optimal-and OUP is at the top. The strategy then lists specific publishers with attractive platforms as representing the next best options, and ends with general aggregators ranked in order of preference as the least desirable options. The e-books acquisitions decision tree also indicates which publishers and vendors the library will not deal with and states why.

\section{TRLN/OUP Partnership Background}

Development of this pilot goes back to 2009 when UNC and OUP began conversations on what libraries needed publishers to do for them to move acquisitions from print to e-books and what would constitute a mutually acceptable and sustainable cost model. The initial step in building the requisite trust relationship was sharing information that publishers and libraries rarely do on monographic purchases by having YBP provide these data as a trusted neutral third party. Over the course of decades of cooperating, TRLN librarians learned that "honest and open communication between librarians from different institutions" was an essential element of their success; ${ }^{18}$ such a relationship is also a prerequisite for creating deep and effective partnerships between librarians and publishers.

After UNC shifted its intake of OUP monographs in the sciences from print to ebooks on the UPSPO platform with 2010 imprints (and in the process bought the entire archive for all subjects then available), the two parties kept their conversation going. The resulting deep relationship and OUP's openness to experimenting with e-books were factors that led to it being invited to participate in the 2011 TRLN Beyond Print symposium. ${ }^{19}$ This gathering, funded by the Andrew W. Mellon Foundation, provided the immediate background to develop new business models and licensing terms for consortial acquisition of e-books. ${ }^{20}$

TRLN librarians were seeking to identify a major publisher for a consortial e-books pilot, preferably one whose publishing output spanned a large number of subjects. Simultaneously, OUP was looking for libraries willing to experiment with consortial ebook acquisitions. In selecting potential partner publishers, TRLN considered early on the level of overlap in acquisitions within the consortium, using data from YBP. When TRLN analyzed aggregate purchases from OUP and other publishers on the UPSO platform, it realized not only that member libraries were acquiring a very high proportion of all these titles in print but also that massive duplication existed both within the consortium and among individual libraries on each campus. Conversely, TRLN's e-book intake from OUP and its USPO publishers was minimal before this pilot began in April 2012 - which represented a past acquisitions pattern rather than a future desideratum. 


\section{TRLN Consortial E-books Acquisitions Guiding Principles}

The primary goal of the pilot was to move TRLN libraries and partner university presses to an electronic environment for books that enhances support for instruction and research. Within the context of changing the mix of book formats that consortial libraries collectively purchase and UPSO publishers sell to reflect an overall shift to e-books, the project was designed to ensure that TRLN acquires the complete monographic output. This model increases the scope of these publishers' print and e-books available to patrons on each campus, with each TRLN campus individually and separately owning every electronic title in perpetuity and collectively having at least a single shared print copy of nearly every title not on the UPSO platform. In tandem with this pilot, OUP made TRLN an attractive offer to purchase the entire corresponding e-books archive for titles not yet owned, which both UNC and Duke University accepted.

Pilot publishers are guaranteed sales of all their books, and users are guaranteed access - with the TRLN libraries funding these acquisitions off the top of their budgets as a collections priority. Although such a cooperative acquisitions model minimizes print book sales to TRLN absolutely, it is not designed to reduce the level of acquisitions or save money by cutting global monographic expenditures. In fact, TRLN guaranteed OUP and, by extension, its participating publishers that they would not experience a net loss of library revenue from changes in the numbers and kinds of books sold to the consortium collectively. At the same time, OUP did not expect to increase aggregate sales revenues from TRLN. Such parallel promises reinforced the central goal of shifting the balance of monographic acquisitions to e-books over time on a financially sustainable cost-neutral basis, adjusted for changes in the amount of content vended.

Because the TRLN/OUP pilot was not intended primarily as a buying club but evolved within the context of a long history of cooperative programs to provide comprehensive collections to all campuses on equal terms, it did not require complex, time-consuming, and politically contentious mechanisms for sharing costs among member libraries. Since this program was predicated upon being cost neutral, TRLN used pre-existing expenditure data on monographs from these presses that YBP provided as the most equitable basis to arrive at an acceptable division of costs among the four campuses. The consortium has continued to use the same metrics of sharing costs for subsequent years.

TRLN also leveraged this pilot to extend its cooperation beyond the resources themselves to realize efficiencies in technical processing through shared MARC records maintenance whereby one institution catalogs the print or e-books for all four campuses, which is possible since each member library individually or collectively owns the same titles. The use of publisher-supplied MARC records and metadata as well as vendor-supplied bibliographical and (for print copies) shelf-ready physical processing further reduced global TRLN staff costs while saving shelving space because of single shared print copies and lowered net consortial physical acquisitions.

Through this pilot, librarians and publishers learned how to incorporate book vendors such as YBP as critical and necessary links between partner presses and consortial libraries in a publishing universe that involved both electronic and print components being acquired in tandem. The process began with YBP acting as the trusted neutral third party in providing title and financial data on participating publishers' sales to TRLN and the consortium's expenditures on these presses' output and ended with its handling of the invoicing. TRLN libraries thereby achieved a better understanding of what they were buying from this subset of publishers, while OUP for the first time knew what a specific group of libraries was acquiring.

YBP played an essential role in defining the universe of participating publishers' monographic output through its book-profiling capabilities, including those titles not 
available as e-books as well as e-books not on the UPSO platform. It thereby ensured TRLN would achieve complete monographic coverage and kept unintended duplication to a minimum. Within a model where libraries are acquiring the entire publisher output, the value of a vendor increases because it coordinates the acquisition of e-books in tandem with print in addition to its traditional role of billing for purchases and shipping appropriate physical copies.

In summary, the TRLN/OUP pilot encompassed new and innovative ways of identifying, pricing, acquiring, processing, and sharing both print and e-books consortially. The program also entailed major educational and informational efforts for the scores of subject librarians on the four TRLN campuses so they would understand what content is being acquired and how this pilot impacts their role as selectors, while ensuring that they are able to explain such a novel collections approach to faculty and students.

\section{Identifying and Mastering the Challenges}

TRLN, OUP, and YBP are discovering together what it takes to expand cooperative collection development to include wholesale acquisition of thousands of print and e-books annually as an integrated program. Issues have been numerous and not all have yet been fully resolved, given the limits of the systems needed to manage such a complex endeavor and the efforts required to develop new capabilities and practices. While those involved in the planning generally were aware of the challenges discussed below, the scale of this pilot and the centrality to the academic enterprise of these monographs underscored the significance of these issues and need to address them adequately and quickly. All parties have learned crucial lessons and have decided to continue the program.

Although librarians and publishers have been dealing with monographs in tangible formats for centuries, print turned out to be more problematic than e-books. The "original sin" of the pilot was the failure to fully use YBP's extensive profiling capabilities to limit shared print books to only what the consortium really needed. As a consequence, TRLN initially acquired titles such as expensive reference works that it would not have wanted in tangible formats under any circumstances-much less when they were located in an offsite facility. The cost of shared print acquisitions led to overspending the projected budget for the first year by 5 percent. In addition, the complexities of calculating differential print discounts based on the number of copies the consortium acquired entailed a great deal of time and effort on YBP's part that turned out not to be justified and would not be continued in the second year of the pilot.

While TRLN has been successful in modifying its technical processing to make these print and e-books available to users quickly, it needed to create mechanisms to speed up the delivery of shared print copies that users request from the common offsite facility where they are housed but that was designed to operate for low-use retrospective collections rather than new books with higher levels of circulation. As part of an ongoing assessment, the consortium continues to review document delivery mechanisms to ensure that these offsite shared print titles are made available promptly to be acceptable to readers in lieu of local onsite holdings. TRLN also had to establish clear and uniform policies covering circulation, renewals, and recall for shared print copies as well as specify restrictions explicitly (for example, shared print copies cannot be used for reserves).

As a prerequisite for effectively vending e-books, OUP realized the critical need to upgrade its UPSO platform to release packages more often than 3-4 times during the year to eventually providing titles individually as soon as each becomes available. It also came to appreciate the necessity of informing YBP of new and forthcoming e-books ASAP - as it already did with print titles-especially when the e-version is released 
before print. As part of this process, OUP is now including eISBNs in its data feeds to YBP so that titles on the UPSO platform will appear in its GOBI bibliographical database much sooner. The inability of librarians to know sufficiently early what print and e-books will come on the pilot and when they will be available has been a major source of confusion and frustration, which reinforced the pressure on OUP to enhance the UPSO platform and YBP to provide this information in GOBI.

OUP heard repeatedly about the importance of speeding up the UPSO platform response time so that readers can quickly access e-books to make the shift from print more acceptable. The benefits of having the UPSO platform accommodate multiple DRM regimes so TRLN potentially can expand the pilot to acquire single simultaneous user e-books also became evident. (Currently, single-user e-books are available only via general aggregators, which is neither optimal nor for some TRLN libraries acceptable except in extreme cases.)

Given the visibility and importance of university press monographs, OUP has come to understand how crucial it is to inform YBP when the e-book is incomplete (for example, missing images or integral components such as a supplemental DVD bundled with print but not incorporated into the e-version), so librarians will know when ebooks are unacceptable substitutes for print. YBP in turn has learned how essential it is to convey this information to library customers in its book profiling via GOBI and not just apply the print monographic data to the e-version.

More broadly, TRLN repeatedly and emphatically stressed to YBP the need to profile e-books quickly and not have it dependent upon - and often delayed by - the profiling of the print version. By having the information indicated above available sooner, YBP should be able to block notifications for titles that will come on the TRLN/OUP a priori-as opposed to only being able to control for duplication afterward.

It also became clear to all that vendor databases such as GOBI need to have and display information on both print and e-book availability ASAP - even if the titles are not yet fully profiled or released. In part because of this pilot, YBP upgraded GOBI to redefine its consortial functionality to distinguish between print and e-books as well as provide better indications regarding whether the TRLN libraries would receive a title; the format(s) in which they would receive it; and when it would arrive/become accessible.

\section{Librarian Concerns and Patron Reactions}

Addressing subject librarians' frustrations about when print and e-books would arrive and become available, along with concomitant fears about potential negative faculty and student reactions, became a major ongoing issue. Librarians closely involved in this project repeatedly had to convey these concerns to OUP and YBP, while simultaneously reminding selectors that TRLN was experimenting with a new consortial model being created on the fly and therefore subject to glitches.

Some subject librarians were overly cautious and unduly fearful about shifting so quickly and decisively to e-books-more so, in fact, than patrons. Duke University had witnessed this phenomenon a year earlier when its YBP approval plans moved to e-preferred. Subsequent analysis revealed that 97 percent of the requests to duplicate e-books with print copies came from the subject librarians, while patrons accounted for only 3 percent. ${ }^{21}$ More broadly, a recent survey indicated that librarians might be more cautious about -if not actually reluctant in-accepting e-books than faculty. ${ }^{22}$

At UNC, a clear and consistently reiterated evidence-based collections philosophy within an entrepreneurial environment of calculated and bounded risk helped bring subject librarians along. Moreover, selectors were emphatically advised to buy duplicate local copies of print books from pilot publishers whenever users raised concerns - es- 
pecially since such requests rarely occurred. This policy reinforced a parallel message that exceptions were not going to drive the system and would be dealt with promptly if and when they occurred rather than anxiously anticipated.

Eventually, most of the ten separately administered libraries on the four campuses belonging to TRLN had YBP cease generating new book notifications for titles that would come on the pilot. Although this change was expected from the beginning, its implementation reduced ongoing subject librarian irritations with the OUP platform and the YBP database by no longer automatically calling to selectors' attention books that would eventually come on this pilot. Ceasing notifications also made it more difficult and expensive in time and effort for selectors to identify titles from these publishers and thereby buy them preemptively.

The absence of faculty concern about this shift to e-books, together with few patron requests to duplicate shared print copies locally, have been decisive in allaying subject librarians' fears. Continuing the pre-existing approval plans that automatically bring in print books by campus authors and/or those high-visibility, high-use titles covered in major review media such as New York Times Book Review, TLS, and Science undoubtedly contributed to the minimal level of patron concerns and requests to buy duplicate print copies locally.

Users' acceptance of the shift to e-books went hand in hand with the low circulation thus far of the shared print titles. Whereas 43 percent of e-books were accessed between August 2012 and January 2013, shared print usage has been much lower. Certainly widespread access to e-versions reduced circulation of print analogs, as only 18 percent of the shared print requests were for titles available on UPSO when the patron made the request. The higher use of e-books in general and corresponding OUP print monographs specifically has been long established, having been documented in the earliest usage reports conducted in the 1990s. ${ }^{23}$ The TRLN pilot, however, is the first study to measure the use of e-books in relation to offsite print versions.

UNC librarians have speculated that, because major research libraries provide such a large array of e-resources and couple these digital collections with robust discovery options, users have come to rely on instant access. This experience mirrored other studies that "have observed a greater level of usage after an e-book collection had gained acceptance upon reaching a critical mass in which students and faculty begin to find more and more relevant information." ${ }^{24}$ Consequently, patrons are accustomed to using e-books earlier and more often than their print analogs-especially since they would have to physically retrieve the latter and (for shared print located offsite) also have to wait to get the physical copy. In addition, even the minimal effort to complete an online document delivery request form could discourage some users.

The delayed use of print books when e-versions are available correlates with another temporal relationship: readers use e-books to assess whether it is worth reading the print analog. As a recent reviewer of e-book usage surveys noted, "e-books may also be employed, particularly in the book-dependent disciplines, as a convenient way of previewing a book without leaving one's work station. If the e-version seems promising, then one can search out the physical book." Conversely, the reviewer observed when a reader reaches a negative conclusion after consulting an e-book, this outcome would further depress print book circulation..$^{25}$ To more fully document and understand this phenomenon, TRLN plans to conduct further research after more longitudinal data becomes available.

This temporal differential relates to more general questions regarding use of print books versus e-books that go to the heart of the pilot's framework to initially couple the acquisition of all e-books on the UPSO platform with the large-scale provision of a single shared print copy in the humanities and social sciences. Such a decision 
allowed TRLN to bypass the perennial format fetish debates about e-books versus print books.

Compounding this false dichotomy between print and e-books are forced-choice questions and surveys predicated upon patron preferences without the necessary contextual background. Even patrons who state a categorical preference for print books typically favor e-books in case of reference works, monographs consisting of articles such as collected editions, festschriften, conference proceedings, and even long-form texts where the use of content is in "digestible chunks" such as reports and collections of documents. The consistency of this finding is so typical that it is summed up by the formula of "use rather than read." 26

When consortia contemplate a wholesale shift from print to e-books, librarians also need to realize that long-form print books are not necessarily - or even ordinarily - read cover to cover. A study of UNC and Duke University researchers done nearly twenty years ago before the advent of e-books found that 80 percent of the interviewees read only a small portion of the monographs and articles consulted. ${ }^{27}$ If TRLN replicated this survey now, this situation probably would be even more pervasive today.

Most significantly and relevant to the TRLN/OUP pilot, a fundamental difference exists between what patrons might prefer in theory and what they will accept in reality. Even users who state an unqualified preference for print over e-books typically are willing to accept the latter in lieu of the former, because they "will use whatever medium is available." ${ }^{28}$ Undoubtedly, such reader behavior explains in part UNC's longer experience and the more recent TRLN evidence of patrons rarely requesting the library buy a duplicate print book when an e-version is available.

The success of TRLN's shift to digital monographs without protests has been predicated by the growing acceptance of e-books across the disciplinary spectrum, with a recent University of California Library study indicating that 34 percent of respondents preferred e-books, while 17 percent had no preference or described a preference that is usage-dependent. ${ }^{29}$ Acceptance also has been enhanced by how e-books increasingly are used. In particular, the growing prevalence of tablets or other mobile devices makes reading e-books more comfortable and could actually result in increased patron demand for digital monographs. ${ }^{30}$

Wholesale movement to e-books with faculty agreement therefore can and should happen when librarians sense users would accept such a change-especially if coupled with continued targeted print acquisition of high-visibility/high-use titles and ondemand acquisition of print duplicates. Such a philosophy undergirded UNC's moving its Springer and OUP monographic acquisitions in the natural sciences to e-books in lieu of print several years ago. The same mindset was behind the TRLN pilot's shift to e-books across the disciplinary spectrum, with the addition of the large-scale print duplication component in the humanities and social sciences. Thus far, users have accepted this change, and the patron surveys cited above indicate that librarians elsewhere should also be able to move forward similarly with the overall shift in monographic acquisitions to e-books.

\section{Moving to the Next Stages}

After evaluating the content acquired, together with the corresponding financials and usage metrics, in May 2013 TRLN decided to continue this pilot for another twelve months and expand it to include all additional publishers and all new e-book packages on the UPSO platform. In May 2014, TRLN extended this program for another year and again expanded it to include all new UPSO presses and their output.

The pilot has succeeded in its primary goal of shifting TRLN's monographic acquisitions from print to e-books. Before this program, TRLN was acquiring less than 
1 percent of all monographs from these publishers as e-books. By the end of Year 1, the percentage of e-books acquired surged to 72 percent: that is, each TRLN campus acquired 2,003 titles as individually and separately owned e-books (representing a total of 8,012 electronic copies) and 3,088 titles as collectively owned shared print copies, for a total of 11,100 copies. By the end of Year 2, 79 percent of the 14,157 copies TRLN acquired represented e-books.

To keep net costs constant (adjusting expenditures to include the acquisitions from the new publishers and new e-book packages into the pilot and away from individual library approval plans) and therefore sustainable, in subsequent years TRLN revised its consortial profile with YBP to reduce the intake of print that duplicated e-books being acquired to the greatest extent possible. It probably would have done so regardless of budget constraints, because experience demonstrated that shared print titles have been the most problematic, confusing, and time-consuming component of this program. They have been rife with problems, from identification and budget prediction, to explanations for subject librarians, to actual acquisitions and physical processing, and to problems with providing timely access from the shared offsite facility.

In addition to avoiding print duplication in all the STEM (science, technology, engineering, and medicine) fields without exception when a title is on the UPSO platform, for subsequent years the pilot TRLN took greater advantage of YBP's profiling capabilities to eliminate duplicate print copies in selected humanities and social sciences subjects where users are most likely to accept e-books in lieu of print (such as business, education, journalism, psychology, public administration, and social work) and in categories where e-versions are acceptable such as reference works, conference proceedings, books consisting of articles or separately authored chapters, and shortform monographs). To further reduce costs, it shifted print acquisitions to paperback preferred.

The TRLN/OUP program indicates wholesale faculty and student acceptance of offsite shared print copies of even university press monographs when coupled with rapid delivery, as long as a library continues to duplicate locally a subset of print titles with high visibility and use. Moreover, circulation of shared print monographs continues to be relatively low, especially for those titles also available as e-books. This consortial experience has confirmed that acquiring print books when e-versions are available can be minimized without sacrificing user satisfaction.

More broadly, whereas research libraries' collection options are typically characterized as just-in-time versus just-in-case, the TRLN/OUP experience has demonstrated that, given acceptable content, cost, and usage inflection points, the optimal consortial solution for key publishers would be to do both: broad just-in-case en bloc acquisitions (for electronic) and narrow evidence-based just-in-time (for print) - with any delays in acquiring or delivering the latter being made acceptable in part by the former's digital availability.

\section{Learning from and Moving beyond the Pilot}

While crafting consortial e-books-and-print deals with core "publisher aggregators" that offer both their own and other similar presses' imprints on library- and user-friendly platforms remains at the top of UNC's e-book strategy, it also plans to experiment alone or with TRLN to create e-only win-win sustainable acquisitioning models with major publishers as well as incorporate general aggregators for the remaining relevant English-language presses as the final element in its staged transition from print to epreferred monographic acquisitions.

Following agreement to continue the TRLN/OUP pilot and emboldened by the lessons learned from it, UNC has moved to wholesale e-only monographic acquisitions 
for additional major publishers that offer substantial price discounts when it already was acquiring most of their monographic output as print books. UNC used special year-end funding to acquire the complete e-books archives (including 2013 releases) for Harvard University Press and SAGE as well as Wiley's 2013 e-books packages in the humanities, natural sciences, and social sciences/law. It subsequently stopped all approval plan print auto-shipments (except for books by campus authors and titles appearing in major review media) as well as new book notifications covering these publishers for the remainder of the calendar year. By 2015, UNC was spending several hundred thousand dollars annually on complete e-books frontlist collections.

UNC and possibly TRLN intend to acquire the entire e-books output of key publishers with which they can negotiate mutually beneficial deals on the model with OUP. Monographs from other presses increasingly will be converted to e-preferred into terms of auto-shipments on scaled-back approval plans or consigned to demand-driven acquisitions (DDA) programs. Consequently, TRLN libraries will not only acquire fewer of these other publishers' books but do so only after they register sufficient use. Moreover, given that ongoing costs for databases and e-journals represent constantly growing portions of collections budgets and the e-books "big deals" are funded off the top of much of the remaining funds for monographs, over time the TRLN libraries will not only have relatively fewer dollars to spend on books from publishers that fail to negotiate comprehensive deals but may even have to restrict DDA expenditures on these titles to keep within budget.

While the high level of monographic duplicate acquisitions within TRLN made OUP the top candidate for a cooperative e-books pilot, it subsequently rejected a consortial general DDA pilot because of low overlap in aggregate acquisitions. ${ }^{31}$ Precisely because TRLN has been so successful in minimizing overall print book duplication within the consortium from the large universe of publishers that YBP profiles, each campus moved to create its own DDA based on its particular needs.

In early 2014, UNC brought up a DDA for trade publishers with EBL via YBP. In early 2015, UNC intends to bring up another DDA for university presses (exclusive of the UPSO publishers and others whose entire e-books output it already is acquiring on financially advantageous terms). While UNC is prepared to go alone on this university press DDA, it intends to work with TRLN to learn if sufficient acquisitions overlap exists for a subset of these university presses to justify a consortial pilot.

Finally, because not all monographs are or will be available as e-books, UNC would like to bring up a print DDA with YBP as another element of its broader user-focused, evidence-based, and metrically informed collections philosophy. Given TRLN's long history of successful cooperation for tangible media, it seems only logical that its members would experiment with completing the evolution to e-books-and in part financing it-by further rationalizing and restricting collective print acquisitions to a single DDA shared copy located in a common offsite facility. Such a consortial program would take TRLN back to its roots of cooperating on print-but with this monographic format now representing only a niche collection in relative and eventual absolute decline as an intellectual and informational resource for supporting the academic enterprise.

\section{Prologue as Epilogue}

In 1933 forward-thinking university leaders at UNC and Duke University - the original TRLN members - formed a Joint Committee on Intellectual Cooperation that issued a document proclaiming that they "are confronted with obligations and opportunities which they can meet adequately only through a program of cooperative endeavor." They went on to observe that, although their libraries "are already the largest in the Southeastern States, neither had nor will be able to provide for a 
long time to come the materials for study and research found in the great libraries of the North and East." 32

This vision has motivated and guided TRLN librarians over the decades and been central in building their collections cooperatively. Insofar as librarians measure how good their collections are by how much they contain, over the "long time" of nearly a century only Harvard University now exceeds the number of unique titles in TRLN collections. ${ }^{33}$ The TRLN/OUP project not only continues this tradition but also has expanded it to capitalize on the potential benefits of cooperating in the acquisition of digital resources-including both frontlist e-books and archive purchases that grew out of this pilot. The collection benefits from this deep partnership with OUP also go beyond current faculty and students to include alumni access to all these e-books at no additional cost, which TRLN would request from other publishers and vendors when it negotiates similar deals.

\section{General Observations \& Conclusions}

In fall 2014, TRLN and OUP reconceptualized their arrangement from an experimental pilot they renegotiated annually to a permanent program with dedicated library funding off the top of the collections budget on the model of an e-journals "big deal." Looking back over the previous three years of efforts to address the dual challenges e-books pose to building monographic collections consisting of both digital and print books and doing so through consortial cooperative collection development programs, TRLN has learned the following lessons that should prove useful to other libraries interested in pursuing similar ventures.

First, consortia can successfully create models for collectively acquiring e-books on a large scale that are workable for both libraries and publishers and that result in acquisitions shifts to digital monographs that are acceptable to users. However, to do so requires taking nuanced and flexible approaches and understanding the dynamics of how patrons use e-books.

Second, librarians, publishers, and vendors need to understand and accept the experimental "Wild West" nature of e-books publishing, vending, licensing, pricing, and accessing. Specifically, no standard models exist-and whatever is in place at any time will be subject to constant and often unpredictable flux. Consequently, all parties must be willing to experiment and be prepared to change agreements based on experience and new circumstances.

Third, to build workable models for acquiring e-books with needed print, all parties need to recognize consortially the valid and often competitive interests involved. Moreover, these complexities include differences among the members of the library consortium and will involve compromises in individual institutional positions to achieve a new model of cooperative collection building and management.

Fourth, librarians, publishers, and vendors must be willing to invest significant time and effort to have an ongoing and meaningful dialog beyond what traditionally takes place. Given the complexities of e-books, coupled with selective but necessary duplicate print acquisitions, all parties need to be prepared to have frank and at times difficult conversations to achieve mutually beneficial outcomes that will advance their common goal of improving support for the academic enterprise.

Fifth, librarians must be prepared to spend the time, effort, and political capital (re-) educating staff to change attitudes, revising policies so these innovative approaches work, and creating new assessment methodologies to measure success. The solution may also necessitate creating a joint repository for the shared print component, as in the case of TRLN, or a distributed responsibility for collecting needed print duplicates as in the case with OUP's similar endeavor with the Manhattan Research Libraries Initiative (MaRLI). 
In conclusion, building cooperative collection development partnerships for e-books with needed print is a moving target that is difficult and time-consuming to master. Fundamentally, this endeavor involves creating new approaches predicated upon deep relationships and a willingness to accept bounded risks related to both content and cost. At the same time, the TRLN experience demonstrates that by working together librarians, publishers, and vendors can succeed in creating a shared and flexible ecosystem encompassing both print and e-books that is efficient, equitable, and sustainable. As such, this program provides a blueprint others can follow to achieve similar success.

\section{Notes}

1. See, in particular, William H. Walter, "E-books in Academic Libraries: Challenges for Sharing and Use," Journal of Librarianship and Information Science 45 (2013): 1-11; Jeff Staiger, "How E-Books Are Used: A Literature Review of the E-Book Studies Conducted from 2006 to 2011," Reference and User Services Quarterly 51 (2012): 355-65.

2. Jeffery D. Carroll and Melissa J. Goertzen, E-Book Program Development Study: Quarterly Report June 1-August 31, 2013: 14, available online at http://academiccommons.columbia.edu/ item/ac:166014 [accessed 22 December 2014].

3. Sarah Buck Kachaluba, Jessica Evans Brady, and Jessica Critten, “Developing Humanities Collections in the Digital Age: Exploring Humanities Faculty Engagement with Electronic and Print Resources," College E Research Libraries 75 (2014): 102, 104, doi:10.5860/crl12-393.

4. Roger C. Schonfeld, Stop the Presses: Is the Monograph Headed toward an E-only Future? (New York: ITHAKA S+R, 2013): 6, available online at www.sr.ithaka.org/sites/default/files/files/ SR_BriefingPaper_Presses_120913.pdf [accessed 22 December 2014].

5. Cynthia L. Gregory, “'But I Want A Real Book': An Investigation of Undergraduates' Usage and Attitudes Towards Electronic Book," Reference \& User Services Quarterly 47, no. 3 (2008): 270, doi:10.5860/rusq.47n3.266.

6. Explanation of this software and how the system works is available online at http://occamsreader.org [accessed 25 December 2014].

7. Compare the print preference a decade earlier in Gregory, "But I Want a Real Book," with the 2014 Student Monitor where, "Today's college students, much like most professionals, feel comfortable in front of a screen. A majority said they preferred a digital format when reading, studying, taking notes, and doing problem sets. That preference for digital was most emphatic when it came to doing research, with 92 percent of students saying they preferred working on a screen." Quotes from "5 Things We Know about College Students in 2014," Chronicle of Higher Education (Dec. 17, 2014), available online at http://chronicle.com/blogs/wiredcampus/5-things-weknow-about-college-students-in-2014/55313?cid=at\&utm_source=at\&utm_medium=en [accessed 22 December 2014].

8. Patricia Buck Dominguez and Luke Swindler, "Cooperative Collection Development at the Research Triangle University Libraries: A Model for the Nation," College E Research Libraries 53 (1993): 485, doi:10.5860/crl_54_06_470.

9. Dominguez and Swindler, "Cooperative Collection Development," 485.

10. Dominguez and Swindler, "Cooperative Collection Development," 486.

11. Planning Initiatives (TRLN, Sept.2011), available online at www.trln.org/planning.htm [accessed 24 December 2015].

12. TRLN: Beyond Print (TRLN, Sept. 2011), available online at www.trln.org/BeyondPrint/ [accessed 25 December 2014]. See also University of North Carolina at Chapel Hill Recommendations on How Publishers, Vendors E Libraries Can Move to E-Books (Draft 8-20-2011), available online at www.trln.org/BeyondPrint/Goals\&Values.htm [accessed 25 December 2014].

13. In addition to OUP, the publishers now include American University in Cairo Press, Edinburgh University Press, Fordham University Press, Hong Kong University Press, Liverpool University Press, Manchester University Press, MIT Press, Policy Press (University of Bristol), Stanford University Press, University of California Press, University of Chicago Press, University Press of Florida, University Press of Kentucky, and Yale University Press.

14. 21st-Century Collections: Calibration of Investment and Collaborative Action, available online at www.arl.org/storage/documents/publications/issue-brief-21st-century-collections-2012.pdf [accessed 25 December 2014].

15. Library Directions: The University of North Carolina at Chapel Hill Library 2005-2010, available online at http://library.unc.edu/wp-content/uploads/2013/07/Plan20071025.pdf [accessed 29 
December 2014].

16. For a comparative study at another university whose author concluded that "acquiring Springer e-books as a big deal has been a good value," see Terry Bucknell, "The 'Big Deal' Approach to Acquiring E-books: A Usage-based Study," Serials 23, no. 2 (2010): 126-34, doi:10.1629/23126.

17. John Slater, "Why Aren't E-Books Gaining More Ground in Academic Libraries? E-Book Use and Perceptions: A Review of Published Literature and Research," Journal of Web Librarianship 4 (2010): 305, doi:10.1080/19322909.2010.525419.

18. Dominguez and Swindler, "Cooperative Collection Development," 488.

19. For an indication of the duration, complexity, and intensity of these discussions, as of 12/29/2014 the author had 435 messages in his OUP e-books e-mail folders and another 785 messages in his TRLN Beyond Print/OUP e-mail folders.

20. For a fuller report on this symposium (the basic background being summarily incorporated into this article), see Sarah Kalikman Lippincott, Stephen Brooks, Aisha Harvey, Judy Ruttenberg, Luke Swindler, and John Vickery, "Librarian, Publisher, and Vendor Perspectives on Consortial E-Book Purchasing: The Experience of the TRLN Beyond Print Summit," Serials Review 38 (2012): 3-11, doi:10.1016/j.serrev.2011.12.003.

21. Ann-Marie Breaux, Nancy Gibb, and Aisha Harvey, "Launching an E-Preferred Approval Plan," presentation at 31st Charleston Conference 4 November 2011, available online at www. slideshare.net/CharlestonConference/launching-an-epreferred-approval-plan-by-aisha-harveyduke-university-libraries\#btnLast [accessed 29 December 2014].

22. Matthew P. Long and Roger Schonfeld, Ithaka S+R Library Survey 2013: 38, 45-46, available online at www.sr.ithaka.org/sites/default/files/reports/SR_LibraryReport_20140310_0.pdf [accessed 29 December 2014].

23. Mary Summerfield, Carol Mandel, and Paul Kantor, Online Books Evaluation Project Final Report (New York: Columbia University, 1999).

24. Alain R. Lamothe, "Factors Influencing the Usage of an Electronic Book Collection: Size of the E-book Collection, the Student Population, and the Faculty Population," College E Research Libraries 74 (2013): 46, doi:10.5860/crl-301.

25. Staiger, "How E-Books Are Used," 358.

26. Staiger, "How E-Books Are Used," 355.

27. Gordon Sabine and Patricia Sabine, "How People Use Books and Journals," Library Quarterly 56 (1986): 406.

28. Sara Grossman, "Students Prefer Print for Serious Academic Reading," Chronicle of Higher Education (July 17, 2013), available online at http://chronicle.com/blogs/wiredcampus/studentsprefer-print-but-not-books-for-serious-academic-reading/44871 [accessed 29 December 2014]. Grossman based this conclusion mainly on the following study of student book format preferences (which also provides a good overview of the recent literature on the topic): Nancy M. Foasberg, "Student Reading Practices in Print and Electronic Media," College \& Research Libraries 75 (2014): 705-23, doi:10.5860/crl.75.5.705.

29. The University of California Libraries, UC Libraries Academic e-Book Usage Survey: Springer e-Book Pilot Project (May 2011), available online at www.cdlib.org/services/uxdesign/docs/2011/ academic_ebook_usage_survey.pdf [accessed 29 December 2014].

30. eBook Use and Acceptance in an Undergraduate Institution (2013), available online at http:// static.springer.com/sgw/documents/1370809/application/pdf/H6593_CB_WhitePaper_eBooks_ Undergraduate+Inst.pdf [accessed 29 December 2014].

31. Data from YBP revealed minimal overlap among the 10 separately administered libraries on the four TRLN campuses. Specifically, of the 51,168 unique titles, TRLN collectively purchased from YBP in FY2011/2012, 31,276 were acquired by only a single library.

32. A Program of Cooperation (Durham-Chapel Hill, N.C., 1935): 7-9; cited in Dominguez and Swindler, "Cooperative Collection Development," 471.

33. According to ARL Statistics 2011/2012: 54 (adjusted by the author to exclude counts of titles from the Center for Research Libraries), Harvard ranked first with a reported 13,732,301 titles and Yale second with 9,772,319 titles. As of 2/18/2014 the TRLN combined online catalog had $10,350,264$ unique titles. 